\title{
Para entender Marcel Reich-Ranicki
}

\author{
[Understanding Marcel Reich-Ranicki]
}

\section{Klaus Esgensperger ${ }^{1}$}

\begin{abstract}
The article presents the literary critic Marcel Reich-Ranicki and tries to explain his extraordinary success in Germany. It highlights some qualities of his criticism as well as his special relation to mass media and entertainment. Finally, by going into details of his biography, the text surveys the relation of the Polish-born Jewish critic with Germany and German culture.
\end{abstract}

Key-words: literary criticism; German literature; German literary field; Reich-Ranicki

Resumo: O artigo apresenta o crítico literário Marcel Reich-Ranicki e também procura explicar o fenômeno de seu sucesso na Alemanha. Aprofunda algumas particularidades de sua crítica, sua relação com a mídia de massas e o entretenimento. Finalmente investiga o percurso incomum de sua vida como crítico judeu das literaturas de língua alemã nascido na Polônia e sua relação com a cultura alemã.

Palavras-chave: crítica literária; literatura alemã; campo literário alemão; Reich-Ranicki

\section{Introdução}

Quem conhece as críticas de Marcel Reich-Ranicki (1920-2013) pode achar estranho o título desta contribuição. Nenhum crítico literário que publicou em língua alemã é mais fácil de ser compreendido do que ele; escrever e falar ao alcance de todos foi um de seus preceitos. Como fenômeno sociocultural, porém, tem ocupado uma posição singular no campo literário e na esfera pública alemães. Tem sido uma estrela, um star da vida pública na Alemanha. O que quer dizer isso em termos da sociologia cultural? Uma pessoa pode se tornar star dentro da indústria cultural moderna a partir da segunda metade do século XIX. Diferentemente de uma celebridade qualquer, a imagem de um

\footnotetext{
${ }^{1}$ Professor do Departamento de Letras Estrangeiras Modernas e da Pós-Graduação em Letras da Universidade Federal do Paraná. Email: klausegge@gmail.com
} 
Esgensperger, K. - Para entender Marcel Reich-Ranicki

star abrange tanto sua vida pessoal quanto seu êxito profissional. A atratividade de esportistas, artistas ou músicos famosos depende não exclusivamente, mas em boa parte, de seus feitos, de seu trabalho (cf. HüGEL 2003). Reich-Ranicki influenciou a vida literária na Alemanha por cinco décadas e fez sucesso de tamanho tal que, ao final de sua vida, ficou mais famoso do que qualquer um dos escritores de seu tempo que recenseou criticamente. Em seguida, abordaremos três aspectos em torno deste fenômeno: as qualidades e particularidades de sua crítica, a sua relação com a mídia de massa junto com a questão do entretenimento e o lado biográfico - aspectos que nem sempre são separáveis um do outro.

\section{$1 \bigcirc$ crítico}

Em seu ensaio Sobre a crítica literária, Marcel Reich-Ranicki constata, com toda a razão, um déficit de discussão e crítica intelectual na esfera pública alemã desde o iluminismo até o século XX (REICH-RANICKI 2002: 14-17; o ensaio é de 1970). Tradicionalmente, boa parte da classe média na Alemanha hostilizava a crítica pública, que considerava rabugenta, contraproducente ou "corrosiva" (zersetzend). Ser crítico implicava ser traidor da própria cultura e do espírito nacional. Isso culminou na atitude do ministro nazista da propaganda, Goebbels, de proibir a crítica de arte. Em 1936, quando Reich-Ranicki ainda era adolescente e aluno do ensino médio em Berlim, os nazistas substituíram Kunstkritik por Kunstbetrachtung, contemplação "construtiva” da arte.

Reich-Ranicki opôs-se a essas ideias antidemocráticas durante toda sua vida profissional. Gostava da discussão, do debate inflamado sobre pontos de vista contrários. Sempre procurou o grande público, fazendo uso de uma linguagem clara, distinta e compreensível. Na TV, discursando na pose típica com o dedo indicador erguido, deixou a imagem de um especialista apaixonado por literatura que insiste em ter razão; no entanto, mais importante para ele, ainda, era procurar a discussão em si, a troca de argumentos, a polêmica até que se chegasse ao desacordo. Proclamou que o crítico verdadeiro deveria opinar de forma aberta e direta, elogiar ou depreciar a obra em questão, falar sim ou falar não. Consequentemente, publicou uma coletânea de seus ensaios sob o título Lauter Verrisse, que pode ser traduzido por "condenações" (em 
alemão, "criticar duramente" diz-se verreissen; literalmente, "rasgar" em português), e outra chamada Lauter Lobreden - "elogios". No campo literário alemão e na esfera pública em geral, suas críticas duras tiveram muito mais impacto do que seus discursos em louvor de alguém. "A clareza é a cortesia dos críticos" ou "Existem livros bons e livros ruins" são frases atribuídas a Reich-Ranicki que apareceram em muitos necrológios na mídia alemã em setembro de 2013.

Obviamente, essa concepção de crítica implica em forte redução da complexidade de uma obra literária. Colegas e escritores repreenderam Marcel ReichRanicki por ser autoritário e, ao mesmo tempo, banalizar a crítica literária que se destacou na Alemanha, desde o Iluminismo, com nomes como Lessing, Friedrich Schlegel, Benjamin e Adorno. Reprovou-se também o tipo de autoencenação como aparece na capa do Spiegel sobre um romance de Günter Grass (figura 2):

O secundário prepondera sobre o primário com todo poder midiático. Cada vez mais a literatura serve como pretexto para encenar ou ser encenada, criticando ou louvando. Quanto mais alguns provocam barulho, tanto mais forte os outros têm de participar, se quiserem ser ouvidos. (RUOSS 2007: 59; todas as traduções são do autor do artigo.)

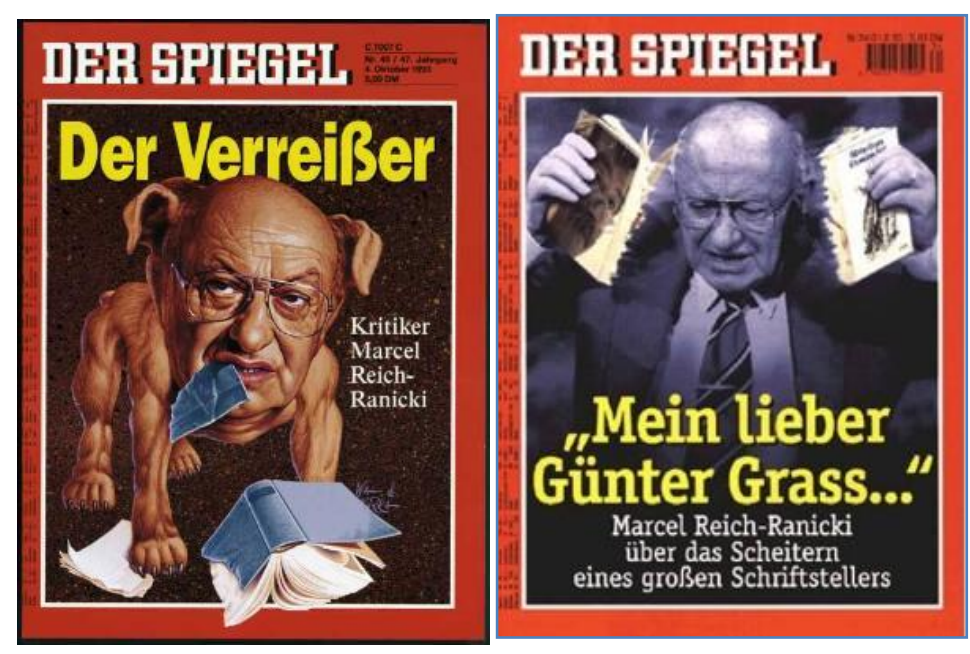

Figuras 1 e 2: capas do semanário Der Spiegel de 1993 e 1995

Reich-Ranicki, por sua vez, partiu invariavelmente do princípio de que existe sempre uma maneira simples de se apresentar matérias complexas, desprezando raciocínios de grande sutileza. Nos anos cinquenta, no clima cultural do pós-guerra, quando começou a trabalhar na Alemanha Ocidental, uma posição como essa não era incomum. Hans- 
Werner Richter, fundador e organizador do famoso Grupo 47, comentou a função da crítica no grupo:

Não éramos uma instituição samaritana. Queríamos reanimar a literatura alemã, a literatura do pós-guerra. Queríamos restabelecer sua importância no mundo. E, para se fazer isso, precisa-se de uma crítica aguda, não se pode trabalhar respeitando tudo, isto é impossível. (apud BÖTTIGER 2012: 270).

Algumas décadas mais tarde, a situação é bem diferente. Apontar defeitos de determinada obra ou falar mal dela é cada vez mais incomum. A recensão crítica que examina e avalia uma produção literária tem cedido lugar ao aviso que mal se diferencia do marketing das editoras (NeuHAus 2009: 205). Atualmente, na mídia em geral, na TV, nos cadernos culturais da mídia impressa ou na internet, dominam recomendações. Na televisão, a escritora e jornalista Elke Heidenreich, que fez sucesso com o programa Lesen! (ler), desistiu declaradamente da recensão crítica em favor de indicações. Iris Radisch, a responsável pela seção de literatura no semanário Die Zeit e, nesta função, uma sucessora de Reich-Ranicki, apresenta Lesetipps (“dicas de leitura”) em vídeos online de aproximadamente três minutos e meio de duração.

Marcel Reich-Ranicki não foi contra esses novos formatos, embora a falta total de qualquer polêmica não combinasse com seu estilo. Desde seu início profissional, identificou-se com a crítica não acadêmica de cunho fortemente jornalístico. Isso provavelmente tem a ver com sua formação intelectual e profissional. Diferentemente dos antecessores ilustres citados acima, e também de colegas críticos contemporâneos do Grupo 47 como Walter Jens, Walter Höllerer, Hans Mayer ou Joachim Kaiser todos professores universitários -, Reich-Ranicki não tinha formação universitária, visto que, na Alemanha nazista, foi impedido de entrar em uma universidade alemã por ser judeu. Mais tarde, compensou essa desvantagem nos círculos intelectuais da nova República Federal com grande diligência, um temperamento ágil e uma retórica tão brilhante como polarizante. $\mathrm{Na}$ interface entre literatura e jornalismo, considerou-se um mediador que dava voz à causa literária na mídia impressa e audiovisual. Viu-se como comunicador de massa, como educador do público (ANZ 2010, Literaturkritik) e, também, como educador de outros mediadores no campo literário. A partir dos anos 70, depois da mudança do semanário Die Zeit para o Frankfurter Allgemeine Zeitung $(F A Z)$, convidou vários professores universitários de nome para publicar naquele jornal. 
Esgensperger, K. - Para entender Marcel Reich-Ranicki

Relata, em sua biografia, que lhes ensinou a escrever não como catedrático, mas exprimindo-se de maneira compreensível e divertida. "Fez-se necessário um trabalho educativo discreto e paciente" (REICH-RANICKI 1999: 386), que finalmente teve sucesso. É provável que um ou outro dos seus colaboradores tenha uma perspectiva diferente sobre os méritos deste novo Literaturpapst ou 'papa' da crítica literária, uma designação predominantemente pejorativa na crítica de língua alemã desde Lessing e Börne. Muitos observadores da vida literário-cultural na Alemanha, porém, concordam que Reich-Ranicki se esforçou de maneira bem-sucedida para diminuir a distância entre a crítica literária culta e o público.

Um bom exemplo desse esforço é a Frankfurter Anthologie, que o crítico iniciou em 1974. Ao longo do tempo, até sua morte, publicou semanalmente no jornal FAZ um poema seguido de uma concisa interpretação pessoal de um colega, jornalista, professor ou autor. Chegou a cerca de dois mil poemas (cf. www.faz.net/aktuell/feuilleton/bilder-und-zeiten/frankfurter-anthologie/ 01/06/2014). A ideia por trás disso foi a de popularizar a poesia:

O abismo entre a poesia e o público deveria ser diminuido e, talvez, anulado completamente. E, para não esquecer: queríamos e continuamos querendo mostrar o que o gênero lírico pode e o que ele deve ser - alegria, divertimento, prazer, satisfação. (apud SALAMANDER 2014)

Até hoje os poemas escolhidos são publicados anualmente em livro pela editora Fischer. Assim, tem se formado a maior antologia lírica comentada em língua alemã.

Outro projeto antológico gigantesco, Der Kanon (o cânone), começou mais tarde. Tratou-se de uma iniciativa que nasceu dentro da comunicação de massa para o grande público. O que deveria entrar ou não foi determinado não somente pelo crítico, mas também discutido na mídia. A tentativa de se estabelecer um cânone que não partisse da escola ou da academia foi algo incomum no campo literário alemão. Além disso, o projeto abrangeu também sua implantação, ou seja: entre 2002 e 2006, Marcel Reich-Ranicki divulgou todas as obras escolhidas em formato de livro. Foram editadas as seguintes antologias canônicas por uma importante editora alemã: Romances em vinte volumes, onze volumes de Contos, nove de Literatura Dramática, oito de Poesia e, finalmente, Ensaios em seis volumes. Claro que a lista definitiva das obras representou o gosto do seu editor, sempre em sintonia ou "cumplicidade" (BOURDIEU 1996: 191) 
com o público. "Reich-Ranicki tem apreço por uma literatura que não exige de mais nem de menos de seus leitores. Seu engajamento crítico visa o romance de entretenimento inteligente e culto" (ANZ 2010, Literaturkritik). Experimentos estéticos muito radicais ou literatura de forte engajamento político não obtiveram sua aprovação. Retirou seus modelos narrativos tanto dos romances e contos do século XIX como dos modernistas moderados do século XX, com ênfase em Thomas Mann. Rejeitou autores como Hubert Fichte, Peter Handke ou Elfriede Jelinek, prêmio Nobel do ano de 2004. Também não demonstrou interesse por obras literárias de língua alemã anteriores ao século XVIII, com a exceção da poesia medieval, que o crítico apreciava.

Além de incentivar esses e outros empreendimentos, Reich-Ranicki esteve presente em instituições e comissões literárias encarregadas de premiar autores. Foi, por exemplo, um dos idealizadores - e durante anos chefe do júri - do prêmio literário austríaco Ingeborg Bachmann, importante condecoração para autores contemporâneos em língua alemã. Todas essas atividades demonstram o peso de sua posição na vida literária alemã. Nas últimas duas décadas de sua vida, era comum que seu veredicto positivo a respeito de um determinado livro levasse imediatamente a um aumento significativo da venda deste. Pierre Bourdieu observou para o campo artístico e literário francês:

\begin{abstract}
A única acumulação legítima, para o autor como para o crítico, para o comerciante de quadros como para o editor ou o diretor de teatro, consiste em fazer um nome, um nome conhecido e reconhecido, capital de consagração que implica um poder de consagrar objetos (é o efeito de griffe ou assinatura) ou pessoas (pela publicação, a exposição etc.), portanto, de conferir valor e tirar lucros dessa operação. (BOURDIEU 1996: 170).
\end{abstract}

Marcel Reich-Ranicki soube fazer um nome conhecido e ser reconhecido. Vários necrológios de 2013 apontam para o fato de que $98 \%$ dos alemães dizem já ter ouvido seu nome (p. ex. o necrológio na Süddeutsche Zeitung, http://www.sueddeutsche.de/ kultur/marcel-reich-ranicki-ist-tot-der-mann-der-uns-das-lesen-lehrte-1.1379918-3/ 01/06/2014). No campo literário alemão pós-guerra, ninguém alcançou, junto com o grande público, tanto poder de consagração como Marcel Reich-Ranicki. Isso tem a ver também com sua relação com a mídia de massa. 
Esgensperger, K. - Para entender Marcel Reich-Ranicki

\section{Only entertainment?}

Desde que as mídias de massas audiovisuais se desenvolveram, sua relação com uma cultura literária mais expressiva em países europeus e na América do Norte tem sido conflituosa. Isso vale principalmente para a relação literatura/televisão. Neil Postman constatou para a sociedade americana dos anos oitenta (POSTMAN 2006: 84): "Television does not extend or amplify literature culture. It attacks it." Quando a lógica dominante é a lógica comercial da TV privada - um ponto crucial sobre qual o pesquisador americano discursa menos claramente -,

[...] the problem is not that television presents us with entertaining subject matter, but all subject matter is presented as entertaining. [...] Entertainment is the supra-ideology of all discourse on television. No matter what is depicted or from what point of view, the overarching presumption is that it is there for our amusement and pleasure. (POSTMAN 2006: 87)

Nesse sentido, o sucesso de um defensor da cultura literária culta na mídia televisiva não deixa de ser surpreendente. No entanto, na Alemanha pós-guerra, as emissoras de rádio e TV ainda não estavam comercializadas; eram instituições públicas exclusivas com a missão de não só entreter, mas também de informar e de elevar a formação cultural dos seus ouvintes ou telespectadores. Durante os anos cinquenta e sessenta, boa parte dos intelectuais da Alemanha oriental vivia de trabalhos para a rádio pública, que pagava bem mais do que os grandes jornais (cf. PFOHLMANN 2007: 173; também PEITSCH 2009, cap. 9: Rundfunk und Fernsehen). A rádio e depois a TV públicas forneceram o ambiente ideal para o desenvolvimento do crítico Reich-Ranicki. Embora fosse capaz de escrever ensaios cultos e longos sobre questões literárias, seu lado forte foi o discurso oral. Já no Grupo 47, a apresentação pessoal foi decisiva tanto para o êxito dos escritores convidados, que liam trechos de suas obras para o público de colegas, quanto para o sucesso dos críticos presentes que, depois das leituras, discursavam sobre as qualidades e defeitos das obras apresentadas. Reich-Ranicki aperfeiçoou sua crítica oral durante os encontros anuais do grupo (BÖTTIGER 2012, cap. 13, dá uma avaliação da atuação do crítico no Grupo 47). Na rádio pública, assumiu junto com Hans Mayer, entre 1964 e 1967, o programa Das literarische Kaffeehaus. Nesses quatro anos, os dois críticos debateram com intelectuais e autores conhecidos 
Esgensperger, K. - Para entender Marcel Reich-Ranicki

como Adorno, Bloch, Böll, Walser e Max Frisch. Alguns poucos encontros foram transmitidos pela TV na época; o registro audiovisual do debate entre Mayer, ReichRanicki e Friedrich Dürrenmatt encontra-se facilmente online no site da empresa YouTube.

O programa que contribuiu decisivamente para a fama do crítico foi Das literarische Quartett, transmitido entre 1988 e 2001 pela ZDF, uma produtora e emissora de TV pública na Alemanha. Foi repreendido por vários intelectuais do campo literário por ser populista, banal e simplificador. $\mathrm{O}$ formato previa o debate entre quatro críticos, liderado por Marcel Reich-Ranicki, sobre cinco livros, em 75 minutos. Logicamente, poucos minutos de fala de cada participante por obra não são suficientes para desenvolver uma análise literária. Aliás, é possível popularizar a literatura na televisão sem simplificar e trivializar? O próprio idealizador e estrela do programa admitiu, na sua biografia: “Resumindo: Acontece no 'Quarteto' uma análise razoável de obras literárias? Nunca. Simplifica-se? Sempre. Será que o resultado é superficial? É muito superficial mesmo.” (REICH-RANICKI 2013: 432) O público, por sua vez, gostou desse tipo de divertimento literário-televisivo principalmente pela encenação retórica do apresentador, que sempre opinava de forma insinuante e engajada, e pelas discussões polêmicas entre os participantes. Em junho de 2000, acirrou-se o debate entre ReichRanicki e a sua colega austríaca Sigrid Löffler a respeito de um romance de Haruki Murakami. Löffler, participante do quarteto desde o início, saiu do programa.

Como avaliar esse tipo de popularização do discurso sobre literatura e o procedimento do seu agente Marcel Reich-Ranicki? Trata-se da democratização de um discurso tradicionalmente elitista ou da depreciação de uma disciplina florescida antigamente na interface entre literatura, filosofia, estética e jornalismo? Uma resposta a essas perguntas depende do ponto de vista individual, que nunca é simplesmente singular, mas influenciado pela posição social de cada um e, especificamente, pela posição no campo literário. Escritores renomados, autores vanguardistas, editores, críticos, jornalistas, professores de ensino médio, professores universitários, estudantes de Letras etc., costumam ter perspectivas diferentes. HARTMANN (2011) oferece uma análise valiosa do "Quarteto Literário" em comparação com outros programas literários televisivos, examinando sua iconografia, sua realização cênica no estúdio e os conceitos literários de cada um dos críticos envolvidos. 
Para nós é instrutivo mostrar em um exemplo como Reich-Ranicki justifica sua posição e lida com as contradições inerentes a ela. A respeito disso é importante compreender que certas discrepâncias e incoerências não são simplesmente falhas subjetivas, mas refletem os conflitos nos próprios campos da produção cultural como música, dança, pintura, literatura, teatro etc. Estes, na Europa moderna, encontram-se divididos entre os polos da alta cultura e da cultura popular, e, mais tarde, da cultura de massas. Na Alemanha, costumam-se usar as categorias de E-Kultur para designar a cultura "séria", que é a Cultura escrita com maiúsculo (a expressão é de EAGLETON 2000, cap. 2), e de U-Kultur, a cultura de mero entretenimento, do al.: Unterhaltung, "entretenimento", “diversão". Uma divisão parecida tem estruturado a vida cultural nos Estados Unidos. Embora de forma historicamente diferente e menos impactante, highbrow e lowbrow são os dois polos culturais opostos até hoje. No que diz respeito especificamente à literatura, Pierre Bourdieu (BOURDIEU 1996, passim) analisou o campo literário francês como dividido, desde o século XIX, entre os extremos da autonomia (l'art pour l'art) e da heteronomia (literatura trivial, bestseller), estrutura que não é idêntica, mas que tem relação estreita com as terminologias alemã de $E$ e $U$ e angloamericana de high e low. Na academia, intelectuais como Umberto Eco começaram, nos anos sessenta do século passado, a investigar e publicar sobre produtos da indústria cultural como quadrinhos e filmes de Hollywood. Fascinado pela cultura de massas e pelo movimento pop nas artes, para o professor universitário e crítico norteamericano Leslie Fiedler, o distanciamento da cultura das elites não estava mais adequado aos novos tempos pós-modernos (cf. FIEDLER 1999 [o ensaio é de 1968/1969], com o título programático Cross the border, close the gap). Independentemente disso e partindo de uma agenda político-emancipatória, formaram-se naqueles anos os Estudos Culturais da escola de Birmingham, enfatizando pesquisas em torno dos meios de comunicação de massas.

Apesar desse contexto internacional, o ponto de partida de Marcel ReichRanicki foi bem diferente. Nunca se interessou pela cultura popular ou por produtos da indústria cultural. Sua intenção foi popularizar a crítica literária, e soube usar a mídia para esse fim. Um de seus dez mandamentos como crítico diz: "Nunca causarás tédio" (cf. AnZ, Marcel Reich-Ranickis Zehn Gebote für Literaturkritiker), lema este que já indica maior compatibilidade com a ideologia da televisão. Nos últimos anos de vida, gostava de citar um texto de Friedrich Schiller, "Sobre o uso do coro na tragédia", 
Esgensperger, K. - Para entender Marcel Reich-Ranicki

prefácio à peça $A$ noiva de Messina ou Os irmãos inimigos, de 1803: “Toda arte se consagra à alegria, e não há tarefa mais elevada e mais séria do que tornar os homens felizes" (SCHILlER 2009: 186). Reich-Ranicki cita a frase na introdução da sua antologia de Schiller e também em entrevistas, veja-se o debate com o apresentador Thomas Gottschalk ou sua declaração Ein Satz, den ich nie vergessen habe, ambos de 2008. Será que Schiller, que publicou famosas cartas sobre a educação estética do homem foi, na perspectiva do nosso crítico, um precursor do teatro de revista? ReichRanicki, tão versado em literatura alemã, certamente o sabia bem, mas como mestre da polêmica aguda estava disposto a fingir até mesmo ignorância, de fazer-se de desentendido em favor do efeito retórico. Conheceu Schiller como poucos e sabia que a estética clássica de Weimar sempre procurou afastar-se do popular, condenando o mero divertimento. No prefácio mencionado, Schiller declara "guerra ao naturalismo" (SCHILLER 2009: 190); assim, lança mão da linguagem em verso e reintroduz o coro da tragédia antiga em sua peça. Trata-se de medidas estéticas que visam uma espécie de distanciamento do público um século e meio antes de Bertolt Brecht:

Pois a mente do espectador deve preservar sua liberdade mesmo na paixão mais violenta, não deve ser presa das impressões, mas separar-se sempre clara e alegremente das emoções que sofre. O que o juízo comum costuma censurar no coro, que ele faz cessar a ilusão, que interrompe o poder dos afetos, é o que o torna altamente recomendável, pois é exatamente esse poder cego dos afetos que o verdadeiro artista evita, é essa ilusão que ele desdenha provocar. (SCHILLER 2009: 194)

Nem mesmo diante do maior poder dos afetos, um espectador adulto deveria desligar temporariamente juízo e razão. Schiller obviamente não serve para justificar a indústria cultural que, conforme uma observação de Theodor W. Adorno, tem como inimigo a inteligência de seus consumidores: "O inimigo que se combate é o inimigo que já está derrotado, o sujeito pensante" (ADORNO/HORKHEIMER 1985: 140). A peça A noiva de Messina, aliás, foi considerada pouco acessível e "artificial"; por isso, não tem feito sucesso nos palcos alemães até hoje (SCHULZ 2011: 201).

$\mathrm{Na}$ sua recente antologia de Schiller, Reich-Ranicki incluiu o mencionado ensaio "Sobre o uso do coro na tragédia", a fim de que todo leitor pudesse conhecer o texto completo. Quem faz isso logo percebe que a alegria de que o autor alemão fala é um afeto solene, semelhante àquele de sua famosa "Ode à Alegria". O teatro verdadeiro 
não deveria suprimir a diversão do espectador, "mas enobrecê-lo" (SCHILLER 2009: 186). Nos países de língua alemã do século XVIII, o intelectual que mais contribuiu para a nova autonomia do campo literário foi o kantiano Friedrich Schiller. Mesmo assim, nunca desistiu de certos fins educativos. Somente a literatura e a arte autônomas conseguem cumprir, na sua concepção, os valores humanitários que vêm do Iluminismo e da Antiguidade, da Grécia clássica. A formação do homem para a liberdade deveria acontecer por intermédio de suas experiências com a esfera estética: "Numa palavra: não existe maneira de fazer racional o homem sensível sem torná-lo antes estético“ (SCHILLER 2013: 109).

Reich-Ranicki compartilhava dessa visão de literatura pelo menos parcialmente, mesmo nas últimas décadas de sua vida, quando tanto enfatizava a diversão. Em entrevista ao semanário Spiegel sobre sua proposta do cânone, intitulada "Literatura deve divertir", ressaltou: "Acima de tudo, o ensino da literatura alemã na escola deveria ser divertido. Tudo depende, porém, de divertir os alunos com literatura superior, e não inferior.” (REICH-RANICKI 2001). Esse divertimento ou entretenimento (Unterhaltung), portanto, está ligado a um tipo de educação estética. Não se refere ao entertainment americano, que pode ser definido como "a type of performance produced for profit, performed before a generalized audience (the 'public'), by a trained, paid group who do nothing else but produce performances which have the sole (conscious) aim of providing pleasure" (DYER 2002: 19). No fundo trata-se de conceitos e práticas bem diferentes.

Não podemos prosseguir aqui com a interessante questão sobre como é possível "divertir alunos com literatura superior”, cuja socialização midiática aconteceu dentro do padrão entertainment, que há muito tempo já não se restringe mais aos Estados Unidos, mas domina mundialmente. De qualquer maneira, provocam-se conflitos quando não são consideradas as diferenças básicas entre conceitos diferentes de entretenimento. O que o crítico Reich-Ranicki, no meio da polêmica, omitiu por vezes para justificar seu posicionamento no campo literário, o espectador/ leitor/consumidor Reich-Ranicki nem sempre conseguiu reprimir. Ficou famosa a sua rejeição do maior prêmio da TV alemã (Deutscher Fernsehpreis) em outubro de 2008. Durante o programa, Reich-Ranicki foi o último a receber a homenagem no estúdio depois da exibição parcial e premiação de shows e dramalhões. Além disso, teve de 
Esgensperger, K. - Para entender Marcel Reich-Ranicki

presenciar, por parte da apresentação, todo pintar cor de rosa, toda autoadulação da elite do show business alemão presente na plateia. Não aguentou. Quando foi a sua vez de receber esse prêmio pelo conjunto de sua obra, rejeitou-o publicamente. Declarou que não deveria fazer parte do grupo dos premiados e articulou sua profunda desaprovação, exigindo uma programação mais inteligente.

Articulou-se, dessa maneira, um conflito entre um defensor da cultura literária alemã tradicional e os agentes do popular massivo comercializado. Confirmando diretamente a mencionada tese de Neil Postman, até o protesto contra o estado lamentável da principal mídia audiovisual virou imediatamente entretenimento e contribuiu, assim, para aumentar ainda mais a fama do crítico octogenário. Até hoje existem dezenas de vídeos do YouTube na internet com esse conteúdo.

\section{3 "Minha vida"}

Marcel Reich-Ranicki obteve seu sucesso mais impressionante não como crítico nem como estrela televisiva, mas escrevendo sua autobiografia. Mein Leben, publicada em 1999, vendeu nos primeiros dez anos mais de um milhão de exemplares somente nos países de língua alemã e foi traduzido para 19 idiomas (cf. Internet-Portal Marcel Reich-Ranicki). Seu autor recebeu vários prêmios importantes pelo livro, a trama foi filmada como documentário e, mais tarde, também como longa-metragem (roteirista: Michael Gutmann, diretor: Dror Zahavi). Depois da leitura da segunda parte do livro, que vai de 1938 até 1944, entende-se que, de certa forma, trata-se de um milagre ReichRanicki ter chegado aos noventa e três anos de vida.

Nascido na Polônia, de pai judeu polonês e mãe judia alemã, sofreu as mesmas perseguições que o povo judeu na Europa em geral. Foi deportado da Alemanha para a Polônia em 1938. Depois da invasão alemã foi internado no gueto de Vársóvia, onde trabalhou para a administração judia em razão de seu domínio da língua alemã. Em julho de 1942, quando os nazistas iniciaram a deportação dos habitantes do gueto para o campo de concentração de Treblinka, Marcel Reich foi encarregado de cuidar dos registros. Conseguiu, junto com sua esposa Teofila, escapar do gueto em 1943 e, com isso, da morte certa. Com muita sorte sobreviveu em um esconderijo oferecido por um 
Esgensperger, K. - Para entender Marcel Reich-Ranicki

trabalhador polonês desempregado, Bolek, e sua esposa. Em troca, ajudou na fabricação ilegal de cigarros e contou histórias que lembravam a literatura alemã e outras literaturas do mundo, aplicando assim a arte literária, ou melhor: sua simplificação radical, como meio de sobrevivência (REICH-RANICKI 2013: 227):

Um dia, a mulher de Bolek teve a ideia de que eu deveria contar alguma coisa, uma história empolgante. A partir disso, assim que escurecia, contava diariamente todos os tipos de histórias ao Bolek e sua Genia - durante horas, semanas, meses. Com uma única finalidade: entreter os dois. Quanto mais gostavam de uma história, tanto mais ganhávamos em comida: um pedaço de pão, algumas cenouras. Não inventei essas histórias, nenhuma delas. Antes contava das que me lembrava: na cozinha pobre e escura ofereci aos meus ouvintes agradecidos histórias descaradamente estropiadas, de romances e contos, peças de teatro e de ópera, todos simplificados ao palpite. Contava do "Werther", do "Guilherme Tell", do "Jarro Quebrado", de "Immensee" e do "Schimmelreiter", de "Effie Briest" e "Frau Jenny Treibel", "Aida", "Traviata" e "Rigoletto". Mostrou-se que minha reserva de temas era enorme e suficiente para muitas noites longas de inverno.

Finalmente, o casal foi liberado pelo exército soviético e conseguiu fundar uma vida nova na Polônia pós-guerra. Primeiro, Reich-Ranicki entrou no serviço da polícia secreta comunista e foi vice-cônsul do governo polonês em Londres, onde nasceu o filho Andrew Alexander, em 1948. Sua carreira político-administrativa chegou ao fim dois anos mais tarde por motivo de uma campanha antissemita na Polônia stalinista. Depois de algumas semanas na prisão, reorganizou sua vida e começou trabalhando como mediador da literatura do país que tinha organizado o massacre de grande parte da população judia europeia, inclusive de quase toda sua família e da família de sua esposa. Essa decisão profissional é difícil de entender, mesmo quando se sabe que o jovem já havia passado boa parte de sua infância e toda a adolescência em Berlim onde, em 1938, ainda concluiu o ensino médio, o Abitur (conclusão no Gymnasium, nos anos trinta ainda escola pública da elite/classe média alta). Naquele tempo de antissemitismo aberto e terrorismo estatal crescente, foram a literatura, a música e o teatro que proporcionaram refúgio para o judeu excluído da comunidade do povo alemão, da chamada Volksgemeinschaft. Nem alemão, nem polonês, nem cem por cento judeu (cf. a citação na página seguinte), identificou-se a vida inteira com a arte literária de língua alemã. Quando relata na sua biografia as maiores atrocidades dos alemães nazistas na Polônia, não desiste de pequenas citações literárias de Thomas Mann, Schnitzler, Dante, Shakespeare etc., e também de versos de autores poloneses como Wladyslaw 
Esgensperger, K. - Para entender Marcel Reich-Ranicki

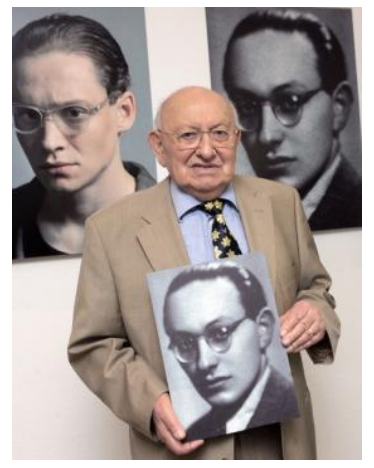

Broniewski. Lembra da vida musical no gueto, resgatando a memória de dirigentes, músicos e cantoras, fossem famosos ou desconhecidos. Evoca assim a cultura burguesa culta na Europa central em contraste às barbaridades dos alemães nazistas.

Figura 3: Reich-Ranicki por ocasião do começo das filmagens do longametragem Mein Leben, em 2008.

Em 1958, Marcel Reich-Ranicki decidiu sair da Polônia comunista e retornar para a Alemanha, dessa vez com a esposa e o filho. Nas décadas pós-guerra, ser judeu na Alemanha não implicava vantagens, pois a sociedade ainda estava impregnada de um antissemitismo que, no entanto, não poderia ser articulado abertamente. O crítico também não fez questão de articular com o público suas experiências com o racismo alemão. Visto que estava precisando de um passaporte válido, até pediu - e conseguiu a cidadania alemã.

Entretanto, a relação da sociedade alemã com o sinistro episódio nazista e com o povo judeu em geral tem mudado bastante. Na vida cultural e especificamente no campo literário alemão, o holocausto e os crimes cometidos durante a Segunda Guerra são temas recorrentes mesmo setenta anos depois dos acontecimentos históricos (EMMERICH 2006: 118). Principalmente a partir dos anos noventa e, no mais tardar, depois da publicação de sua autobiografia, os telespectadores alemães descobriram, com certo espanto, que aquele baixinho esperto que lutava zelosamente, com seu sotaque caraterístico, pela causa literária, era um sobrevivente do holocausto. Sua presença na TV parecia significar para o grande público duas coisas ao mesmo tempo: lembrança da culpa histórica e reconciliação com o povo judeu.

Apesar do sucesso, Reich-Ranicki manteve uma boa dose de ceticismo. Sendo irreligioso, detestava ser restringido a uma identidade judia. Abre sua biografia com uma autocrítica acerca da resposta a uma pergunta que lhe foi feita em 1958 durante a primeira conversa com Günter Grass na Alemanha:

Ele, Günter Grass de Gdańsk, queria saber de mim: 'O que o senhor é, afinal - um polonês, um alemão ou o quê?' Como as palavras indicaram provavelmente uma 
Esgensperger, K. - Para entender Marcel Reich-Ranicki

terceira possibilidade, respondi rapidamente: 'Sou meio polonês, meio alemão e judeu por inteiro.' [...] esta fórmula aritmética fez efeito, mas não era verdadeira: palavra nenhuma estava certa. Nunca fui meio polonês, nunca meio alemão, e não tinha dúvida de que nunca me tornaria um. E nunca na minha vida fui inteiramente judeu, nem hoje sou. (REICH-RANICKI 2013:6)

Nos anos setenta, principalmente a partir de sua nova atuação no jornal $F A Z$, Marcel Reich-Ranicki abandonou um posicionamento político-literário mais de esquerda; até ali, havia defendido a literatura engajada (ANZ 2010, Literaturkritik). Contudo, mesmo tomando publicamente posições conservadoras, repugnou sempre qualquer tentativa procedente de jornalistas ou professores universitários de relativizar o holocausto e os crimes de guerra. Devido a isso, brigou com seu amigo Joachim Fest, um dos editores do FAZ. Tornaram-se famosas também suas brigas com autores renomados como Günter Grass e Martin Walser. O último chegou a publicar, em 2002, depois de muitos anos de relação conflituosa com o crítico, um roman à clef com um protagonista crítico literário judeu que parece uma caricatura malévola de Reich-Ranicki. Morte de um crítico foi o título dado à obra que, pela maioria dos críticos, foi considerada fraca e parcialmente antissemita; uma avaliação instrutiva do debate e da qualificação "antissemita" nesse contexto encontra-se em ScHMitT (2002). Mesmo assim, ReichRanicki inseriu um conto mais antigo de Walser em sua antologia canônica, chamado "Autorretrato como romance policial", onde o próprio autor é um criminoso e seu crítico tem o papel de delegado (cf. ANZ 2010, Freunde und Feinde).

O último grande discurso público do crítico nonagenário que viveu uma vida tão incomum como representativa para a história europeia do século XX aconteceu em 2012. Para lembrar o gueto de Vársóvia e o extermínio do povo judeu, Marcel ReichRanicki falou no Bundestag, no parlamento alemão, diante de uma plateia composta pelos deputados e pela cúpula do governo federal. Engana-se quem acha que, com essa e outras homenagens públicas, o crítico finalmente se sentiria em casa na República Federal da Alemanha. Nos anos setenta, em entrevista com o mencionado Joachim Fest, perguntou-se sobre onde se sentiria à vontade, onde seria a sua pátria. Fechamos aqui nossas considerações com sua resposta tão perspicaz como comovente (apud ANZ 2010, Judentum; cf. também REICH-RANICKI 2013: 296):

Provém de Heine a bela observação que os judeus no exílio tivessem transformado a Bíblia em sua pátria portátil. Da mesma forma, eu não sou, por fim, um ser humano 
Esgensperger, K. - Para entender Marcel Reich-Ranicki

sem terra nem pátria. Também tenho uma pátria portátil - é a literatura alemã, é a música alemã.

\section{Referências bibliográficas}

ADORNO, Theodor W.; HORKHEIMER, Max. Dialética do esclarecimento: fragmentos filosóficos. Trad. de Guido A. de Almeida. Rio de Janeiro: Jorge Zahar, 1985.

ANZ, Thomas. Beiträge im Internetportal Marcel-Reich-Ranicki, 2010. Disponível em: $<$ http://www.literaturkritik.de/reich-ranicki/> (21/02/2014).

ANZ, Thomas; BAASNER, Rainer (eds.). Literaturkritik: Geschichte, Theorie, Praxis. München: C.H. Beck, 2007.

BÖTTIGER, Helmut. Die Gruppe 47. Als die deutsche Literatur Geschichte schrieb. München: DVA, 2012.

BouRdiEU, Pierre. As regras da arte: gênese e estrutura do campo literário. São Paulo: Companhia das Letras, 1996.

CZERNIN, Franz Josef. Marcel Reich-Ranicki oder die Kritik einer Literaturkritik.1995. Disponível em: <http://www.ejournal.at/Kritik/czernin/index.html> (21/02/2014).

DYER, Richard. Only entertainment. 2nd. edit. New York: Routledge, 2002.

EMMERICH, Wolfgang. Das literarische Feld Deutschland - 15 Jahre nach der Wende. In: Revista de Filología Alemana. 2006, 14: 113-130.

FIEDLER, Leslie. Cross the border, close the gap. In: A New Fiedler Reader. Amherst, N.Y. : Prometheus Books, 1999 [1977]: 270-294.

HARTMANN, Rainer: Literaturkritik im literaturfernen Medium Fernsehen. Literaturvermittlung im Spannungsfeld zwischen kritischem Anspruch und TV-Realität am Beispiel des „Literarischen Quartetts" mit Marcel Reich-Ranicki. Marburg: LiteraturWissenschaft.de, 2011.

HÜGEL, Hans-Otto. (ed.). Handbuch Populäre Kultur. Stuttgart, Weimar: J. B. Metzler, 2003.

Internet-Portal Marcel Reich-Ranicki. Disponível em: <http://www.literaturkritik.de/reichranicki/> (21/02/2014).

NEUHAUS, Stefan. Literaturvermittlung. Konstanz: UVK, 2009.

PfOHLMANN, Oliver. Literaturkritik in der Bundesrepublik. In: ANZ/BAASNER 2007: 144-159.

PEITSCH, Helmut. Nachkriegsliteratur 1945 - 1989. Göttingen: V\&R unipress, 2009.

Postman, Neil. Amusing Ourselves to Death: Public Discourse in the Age of Show Business. New York: Penguin, 2006 [1985].

REICH-RANICKI, Marcel. Mein Leben. Stuttgart; München: DVA, 2013 [1999].

. Über Literaturkritik. Stuttgart; München: DVA, 2002 [1970].

. (Hg.). Frankfurter Anthologie: Gedichte und Interpretationen. Frankfurt a.M: Insel, 1985.

(Hg.). Mein Schiller. Frankfurt a.M.; Leipzig: Insel, 2009.

. „Literatur muss Spaß machen.“ Marcel Reich-Ranicki über einen neuen Kanon lesenswerter deutschsprachiger Werke. Der Spiegel 25/2001, 18. Juni 2001. Disponível em:

<http://web.archive.org/web/20081219234638/http://derkanon.de/interviews/spiegel.ht $\mathrm{ml}>(21 / 02 / 2014)$.

Ein Satz, den ich nie vergessen habe. Declaração de 2008. Disponível em: <http://www.faz.net/aktuell/feuilleton/buecher/marcel-reich-ranicki/marcel-reichranicki-ein-satz-den-ich-nie-vergessen-habe-12580041.html> (21/02/2014). 
Esgensperger, K. - Para entender Marcel Reich-Ranicki

Discussão com Thomas Gottschalk, 17.10.2008. Disponível em: <http://www.youtube.com/watch?v=iiEUNeEnJwU (21/02/2014).

RuOSS, Hardy. Erst gefressen, dann gerülpst. Die Literaturkritik und ihre Tischmanieren. Em: Rusterholz, Peter; Zwahlen, Sara Margarita (eds.). Am Ende das Wort - das Wort am Ende? Literatur als Ware und Wert. Bern, Stuttgart, Wien: Haupt, 2007: 47-62.

SALAMANDER, Rachel. Die Zukunft der Frankfurter Anthologie. FAZ, 15.02.2014. Disponível em: $\quad<$ http://www.faz.net/aktuell/feuilleton/bilder-und-zeiten/frankfurteranthologie/lyrik-in-der-f-a-z-die-zukunft-der-frankfurter-anthologie-12802707.html> (21/02/2014).

SCHILLER, Friedrich. A noiva de Messina. Trad. Gonçalves Dias. São Paulo: Cosac \& Naify, 2004.

. A educação estética do homem numa série de cartas. Trad. R. Schwarz e Márcio Suzuki. São Paulo: Iluminuras, ${ }^{13} 2013$.

SCHMITT, Axel. "Herr Reich-Ranicki, in unserem Verhältnis bin ich der Jude". Martin Walsers Tod eines Kritikers und das Antisemitismus-Spiel in den deutschen Feuilletons. literaturkritik.de Nr. 6, junho de 2002. Disponível em: <http://www.literaturkritik.de/public/rezension.php?rez_id=508> (24/04/2014).

SCHULZ, Georg-Michael. Die Braut von Messina oder die feindlichen Brüder. Ein Trauerspiel mit Chören (1803). In: Luserke-Jaqui, Matthias (ed.). Schiller-Handbuch. Leben-WerkWirkung. Stuttgart, Weimar: J.B. Metzler, 2011 [2005]: 195-214.

recebido em: 06/03/2014

aceito em: 01/05/2014 